\title{
O significado socioeconômico do turismo na natureza: o Pantanal diante das normas reguladoras do Estado
}

Recebido: 17.10 .18 Aprovado: 28.05 .19
Cleber J. R. Alho*

Resumo: O Pantanal é um bioma sazonal, de habitats inundáveis, ecologicamente produtivos, com biodiversidade exuberante, que tem atraído o turismo na natureza. Ambiente protegido, é o principal produto do mercado do ecoturismo e seu crescente fator socioeconômico para a gente local. O Pantanal ainda oferece uma complexa diversidade ambiental e biológica, valorando os ecossistemas naturais, o que tem sido crucial para o turismo, ajudando a manter a integridade do bioma. Estudos revelam que alterações e perda de habitats, com conversão da vegetação natural em pastos para o gado e em campos agrícolas, além do turismo não sustentável, são problemas ambientais que afetam a região. Se por um lado o Pantanal merece ter sua natureza protegida, por outro lado, a presença do homem tem levado ao indispensável crescimento socioeconômico, o que inclui o turismo na natureza. Este estudo analisa a percepção em mudança do homem pantaneiro em busca de seu desenvolvimento socioeconômico.

Palavras-chave: Benefício socioeconômico. Biodiversidade. Natureza protegida. Pantanal. Turismo sustentável.

\section{The socioeconomic meaning of nature-based tourism: the Pantanal under governmental regulations}

Abstract: The Pantanal is a seasonal biome of flooded habitats with exuberant biodiversity, which is ecologically productive and has attracted nature-based tourism. A protected environment is the main market product for ecotourism, with a growing socioeconomic factor for the local people. The Pantanal still keeps a complex environmental and biological diversity, valuing the natural ecosystems, which are crucial for tourism, supporting the biome's integrity. Studies reveal that habitat alteration and loss, with conversion of natural vegetation into pasture for cattle ranching and agriculture cropping, and also the non-sustainable tourism, are environmental threats affecting the region. If, on the one hand, the Pantanal deserves to keep its protected nature, on the other hand, human presence favors indispensable socioeconomic growth, which includes ecotourism. This study analyses the local population's perception of achieving their socioeconomic development through growing tourism in nature.

Keywords: Biodiversity. Pantanal wetland. Protected nature. Socioeconomic benefit. Sustainable tourism.

\author{
* Cleber J. R. Alho \\ é professor titular \\ aposentado do \\ Departamento \\ de Ecologia da \\ Universidade de \\ Brasília (UnB); Ph.D. \\ em ecologia pela \\ UNC-Chapel Hill, \\ Estados Unidos \\ da América e \\ pós-doutorado \\ pelo Natural \\ History Museum, \\ Smithsonian \\ Institution, \\ Washington, D.C., \\ Estados Unidos. \\ Atualmente é \\ professor-orientador \\ do Programa de \\ Pós-Graduação em \\ Meio Ambiente e \\ Desenvolvimento \\ Regional da \\ Universidade \\ Anhanguera- \\ Uniderp, Campo \\ Grande, Mato \\ Grosso do Sul, Brasil. \\ Orcid: 0000-0003- \\ 4569-5312. \\ <alho@unb.br>.
}




\section{Introdução}

1

em sido crescente o turismo na natureza no Pantanal nos últimos anos. No Brasil, estudo do Conselho Mundial de Viagens e Turismo (World Travel \&

Tourism Council), em parceria com a Universidade de Oxford, revela que em 2017 o setor movimentou US\$ 163 bilhões, 7,9\% do PIB brasileiro, e foi responsável por 6,59 milhões de empregos (Brasil, 2018).

Em 2014, o turismo cresceu 4,5\% em relação ao ano anterior e movimentou $\mathrm{R} \$$ 316 milhões em Corumbá, às portas do Pantanal (Campo Grande News, 2015). Foram 214.500 visitantes, segundo a Fundação de Turismo do Pantanal, que monitora o impacto do setor na economia corumbaense. Informa ainda que o turismo corresponde a $8,4 \%$ do PIB do município. O setor foi responsável pela geração de quase mil empregos diretos, injetando mensalmente cerca de $R \$ 1,3$ milhões na economia local. A Fundação de Turismo do Pantanal, da Prefeitura de Corumbá, informa que os turistas que chegam àquela cidade têm como destino o Pantanal. No Pantanal de Mato Grosso, segundo estudo sobre o Plano de Marketing Turístico do Pantanal, a permanência média de turistas deverá passar de 4,96 dias, em 2011, para 5,8 dias em 2023. Assim como Corumbá, no sul do Pantanal, a cidade de Cuiabá, ao norte, recebe turistas que se destinam ao Pantanal. O índice de competitividade de destino de turistas da cidade de Cuiabá, medido entre os anos 2008 e 2015, mostra resultado superior à média do Brasil (Brasil, 2015). Os principais destinos do turista que chega a Cuiabá são o Pantanal e a Chapada dos Guimarães, que é parte das terras altas do entorno da planície pantaneira. O crescente fluxo turístico no mundo é revelado pela Organização Mundial das Nações Unidas para o Turismo (UNWTO), que estima, para o ano de 2020, 1,6 bilhões de turistas deslocando-se no mundo todo, desembolsando US\$ 2 trilhões. Ainda segundo a UNWTO, em 2018, um total de 1,4 bilhões de turistas internacionais se movimentaram no mundo e, em 2019, um aumento de 3 a $4 \%$ é esperado (UNWTO, 2019).

O fato é que há consolidada evidência do crescimento do fluxo turístico no mundo, no Brasil e no Pantanal. Enfim, viagem e turismo são atividades que se mostram de significativo crescimento no mundo todo, com estreita relação com o desenvolvimento socioeconômico.

O Pantanal é uma enorme área úmida, localizada na região central da América do Sul (150.355 km²), principalmente no Brasil (cerca de $140.000 \mathrm{~km}^{2}$ ), tocando - Paraguai e a Bolívia. A planície inundável é alimentada pelo rio Paraguai e seus tributários, formando um complexo mosaico de habitats, dando apoio a uma bio- 
diversidade rica e abundante. O bioma conta com sazonalidade anual de seca e enchente, o que o torna altamente produtivo em diferentes habitats naturais, onde ocorrem espécies abundantes e raras. Essa grande produtividade oferece ao visitante a chance de ver aglomerações de aves em ninhais, de mamíferos espetaculares como cervos, capivaras, lobinhos, bem como animais raros, como a onça. Essa rica e abundante biodiversidade, que inclui várias espécies em extinção em outras regiões, tem atraído turistas do país e do exterior, emoldurando um significativo potencial socioeconômico para a região.

A crescente indústria turística no Pantanal, motivada pelos apelos ambientais estéticos da biodiversidade, dos atributos culturais e de recreação, indica essa nova força socioeconômica para a região. A observação de aves, um atrativo de grande interesse internacional, tem também conquistado destaque no Pantanal, junto com outras atividades recreativas, como a pesca esportiva.

O turismo na natureza está relacionado à natureza social do homem. Esse comportamento tem ainda reforço no enfoque da biofilia, que postula a afinidade natural do homem, principalmente do homem urbano, em expressar seu sentimento de prazer e conforto diante da natureza protegida e das formas de vida que participam do ambiente natural (Wilson, 2006: 63). Esse autor argumenta que nossa afinidade pela diversidade de vida é uma essência da humanidade, o que nos remete ao apego aos seres vivos. A teoria da biofilia implica em consequências robustas para o bem-estar da sociedade humana, porquanto indica comprometimento com o mundo natural. Ao contrário, o distanciamento da sociedade humana da natureza e mesmo a destruição dos ambientes naturais têm potencialmente impacto negativo na qualidade de vida, não só material, mas também psicológica e espiritualmente. Diversos estudos que dão apoio à biofilia mostram como o entendimento da sociedade moderna se interconecta com a natureza, indicando que há um engajamento do homem com o ambiente natural, em qualquer lugar, em busca de entretenimento, inspiração, paz pessoal, rejuvenescimento, apoio espiritual e outras recompensas (Krcmárová, 2009: 4-5).

O crescente turismo na natureza no Pantanal tem propiciado o aumento de pousadas e outras acomodações, restaurantes, veículos para transporte dos visitantes a locais de interesse. Além disso, incentiva a frequência de voos para as cidades próximas que dão acesso às pousadas, como Cuiabá, Corumbá, Campo Grande e outros centros urbanos.

Essa tendência relativa à procura por recreação na natureza protegida, com fácil visualização da fauna regional, com incentivo ao desenvolvimento socioeconômi- 
co, tem sido bem destacada em estudos publicados mundialmente para diversas regiões do globo (Sharma et alii, 2012: 10-31).

O turismo compreende variáveis da atividade produtiva tais como apoio à proteção da natureza, infraestrutura para acomodações e transporte, serviços diversos incluindo o papel dos guias turísticos, divulgação do produto, aspectos econômicos e sociais da localidade, dentre outras.

Embora a base da economia do Pantanal seja tradicionalmente a pecuária extensiva, o turismo na natureza vem ganhando espaço e importância para os proprietários de terras da região. Esse fato tem hoje um enfoque relevante. Em passado recente, por exemplo, os fazendeiros do Pantanal empregavam peão especializado em abater onça que predava o gado, seu principal produto para o mercado (Alho et alii, 1988: 166). Hoje, grandes predadores do topo da cadeia trófica, como a onça, são trunfos para a visualização e fotografia pelos turistas no Pantanal, e muitos fazendeiros agora protegem as onças, como seu produto de venda para o visitante (Tortato et alii, 2017: 111-112). É a indicação de um novo enfoque econômico para a proteção de espécies da biodiversidade em seu habitat natural, com benefícios ecológicos e sociais, pois o turista procura a natureza íntegra, o que gera benefícios socioeconômicos para o proprietário das pousadas e seus empregados. Há cálculos financeiros mostrando que mesmo que a onça - agora protegida - ainda que causando danos pela predação do gado, o retorno pelo benefício econômico do turismo é maior (Tortato et alii, 2017: 112).

A interação social entre o turista nacional ou internacional com a comunidade humana do Pantanal proporciona recreação, aprendizado, respeito mútuo, tolerância, conscientização ambiental e outros elos importantes. Por outro lado, o turismo incentiva os benefícios socioeconômicos da região com a criação de oportunidades de empregos e renda para os fazendeiros locais.

Contudo, há impactos negativos causados pela atividade turística, os quais se somam às ameaças ambientais já existentes no Pantanal, e que devem ser analisados para serem mitigados, eliminados, ou mesmo compensados pelo esforço conjunto do governo e dos agentes que exploram o turismo. Para alguns autores, o turismo como indústria sem chaminé é um mito, pois, se não for bem gerenciado, causa danos ambientais em tempo muito curto (Lopes \& Sassi, 2011: 7). Essa postura é ambígua, por ser capaz de proteger o ambiente natural que passa a ser fonte de renda, ao mesmo tempo em que degrada a natureza (Sabino et alii, 2012: 14-15).O governo federal, por meio do Ministério do Turismo, junto com os dois estados cujos territórios compartilham o Pantanal - Mato Grosso e Mato 
Grosso do Sul - tem incentivado e promovido o turismo pantaneiro. Todavia, um crescente número de pousadas não é sequer autorizado ou registrado, não conta com infraestrutura sanitária e coleta de lixo, além de outros problemas.

O objetivo deste artigo é analisar a expansão do turismo na natureza no Pantanal, explorar seu potencial socioeconômico para benefício dos povos locais em relação às normas do estado, da realidade regional e, ainda, propor ações que possam implementar o turismo sustentável no bioma.

\section{Métodos}

Este estudo tem como base a experiência do autor, com mais de 35 anos de pesquisa no Pantanal, reforçada por consulta à literatura publicada sobre o tema.

\section{Discussão dos resultados}

A produtividade dos ecossistemas aquático e terrestre do Pantanal, com sua exuberância, depende de quatro fatores importantes para o turismo na natureza:

i. quantidade de nutrientes carreados pelos rios que vêm do planalto do entorno até à planície pantaneira;

ii. extensão do Pantanal, com toda a complexidade de seus habitats e sua biodiversidade associada;

iii. dinâmica sazonal de enchente-cheia-vazante-seca; e

iv. influência biogeográfica dos biomas vizinhos: Amazônia ao norte, Cerrado a leste, Chaco a oeste, e fragmentos residuais de Mata Atlântica ao sul.

\section{O ritmo da teia da vida no Pantanal}

\section{e a motivação pelo turismo}

O turista que procura a natureza íntegra para seu lazer, além de obter fotografias dos ambientes e da biodiversidade, também procura entender como a natureza funciona no local. Se por um lado o crescente turismo na natureza no Pantanal promove empregos, a elevação do número de pousadas, a educação ambiental e a conservação dos ambientes procurados pelo visitante, por outro lado é relevante que o turista queira explorar o significado, o mecanismo e as relações ecológicas que compõem a complexa teia da vida. 
A diversidade de ambientes naturais e a heterogênea biodiversidade do Pantanal mudam a cada dia e, principalmente, a cada estação desse bioma extremamente sazonal. As espécies da fauna silvestre competem entre si por alimento, nichos reprodutivos e outros recursos, conforme seus habitats mudam em função da sazonalidade de enchente, cheia, vazante e seca. Em alguns anos, cerca de 80\% das terras do Pantanal são inundadas (Alho, 2005: 212; Alho \& Silva, 2012: 592). Por se tratar de um ambiente produtivo, as águas que inundam a região com componentes físico-químicos e biológicos produzem ciclagem de nutrientes que mantém a biodiversidade, com fito e zooplânctons, invertebrados diversos, plantas, peixes, anfíbios, répteis, aves e mamíferos, numa intensa e complexa inter-relação, inclusive com espécies capazes de antecipar mudanças ambientais, reagindo a eventos sazonais.

Esse sistema sazonalmente produtivo contém uma elevada diversidade de plantas macrófitas aquáticas, com cerca de 280 espécies (Pott, Pott, Lima, Moreira \& Oliveira, 2011: 255); com cerca de 2.000 espécies da flora (Pott, Oliveira, Damasceno Júnior \& Silva, 2011:2 65); compondo uma enorme diversidade de habitats naturais (Scremin-Dias et alii, 2011: 277-279); habitados por 269 espécies de peixes (Britski et alii, 2007: 230); 70 de anfíbios e 170 de répteis (Strüssmann et alii, 2007: 73), onde o abundante jacaré-do-pantanal aparece como ícone; mais de 600 espécies de aves e 174 espécies de mamíferos semiaquáticos, aquáticos e terrestres (Alho et alii, 2011: 297).

Habitats terrestres são inundados durante a cheia, com expansão e retração sazonal de ambientes aquáticos e terrestres. Na cheia, os peixes deixam o leito dos rios e se dispersam pelas áreas inundadas para se alimentarem e se reproduzirem (Alho \& Reis, 2017: 25). Na estação da seca, os ambientes terrestres se expandem e são habitados por numerosas espécies de mamíferos, como as abundantes capivaras, os cervos-do-pantanal, lobinhos e muitos outros (Mamede \& Alho, 2006: 993-996). Há oito espécies de primatas na região, sendo o bugio (Alouatta caraya) um dos macacos mais abundantes e procurados pelos turistas para serem observados e fotografados (Alho \& Passos, 2019: 163).

$\mathrm{Na}$ estação seca, com o retorno das águas pelas vazantes aos leitos dos corixos e rios, as depressões no terreno plano permanecem cheias de água, ambientes que são localmente chamados de baías, com enorme concentração de peixes, crustáceos e outros organismos que ali ficam aprisionados. Aí se agregam centenas de aves aquáticas de diferentes espécies, em colônias espetaculares, para se aproveitarem dessa farta oferta de alimento. Formam as chamadas guildas alimentares e também guildas reprodutivas, com os "ninhais", nas árvores próximas, repletas de 
aves se reproduzindo, como o cabeça-seca, a garça-branca-grande, a garça-cinza, o tabuiaiá, a garça-branca-pequena, o tuiuiú, a curicaca, a curicaca-real e o colhereiro, formando grandes colônias.

Há ainda outras espécies de aves que têm estreita relação com as fases sazonais hídricas do Pantanal, como o carão, a biguatinga, o biguá e o tachã. A abundância de espécies de aves é um dos atrativos procurados pelo turista nacional e internacional, especialmente o observador de aves, chamado internacionalmente de bird-watcher. A arara-azul grande, hoje rara em outros biomas brasileiros, é ainda muito abundante no Pantanal. Também no Pantanal ocorrem aves migratórias procedentes de regiões longínquas, como a ave migratória Trinta-réis (Sterna paradisuea), que migra da Argentina para o Pantanal, percorrendo aproximadamente mil quilômetros. Tinga melanoleuca (maçarico-grande-de-perna-amarela), Pandion haliaetus (águia-pescadora), Bartramia longicauda (maçarico-do-campo) e Pluvialis dominica (batuirucu) são exemplos de espécies de aves migratórias que nidificam no Ártico, do Alasca ao leste do Canadá, e migram rumo ao Sul, passando pelas áreas centrais do Canadá e dos Estados Unidos, fazendo parada no Pantanal, algumas delas possivelmente permanecendo como residentes de inverno (Nunes \& Tomas, 2004: 9; WWF-Brasil, 2008: 17-22).Passam determinado período na área pantaneira, retornando depois para os locais de origem. Este constitui outro atrativo para o turista internacional observador de aves.

Além das aves, há diversas espécies que se beneficiam da oferta de recursos ecológicos fartos, como alimento e sítios reprodutivos, exibindo populações vigorosas de capivaras, jacarés, lobinhos, incluindo espécies já oficialmente listadas de extinção, mas ainda lá abundantes, como o cervo-do-pantanal.

Em função desse ritmo sazonal, algumas espécies se dispersam, saindo dos habitats menos favoráveis em termos de oferta de alimento e nichos reprodutivos, enquanto outras se beneficiam. Por exemplo, durante a cheia, as plantas macrófitas aquáticas cobrem rapidamente os ambientes rasos inundados. Nesses ambientes, há proliferação de plânctons, insetos, crustáceos, peixes e outros. Na estação seca, esses mesmos ambientes formam extensos campos cobertos por vegetação terrestre que cresce rapidamente, e que serve de pasto para capivaras, cervos e muitas outras espécies terrestres.

Todo esse ritmo da vida no Pantanal constitui fenômeno natural e atrativo espetacular para o turista. A biodiversidade do Pantanal está adaptada ao calendário sazonal anual, quando as espécies se alimentam e se reproduzem, dependendo da estação do ano. O turista pode entender e desfrutar de diferentes eventos, 
cada um com sua característica, ao longo do ano. Mesmo as plantas do Pantanal variam sua estratégia de produção de flores, frutos e novos brotos, o que serve de alimento para a fauna, dependendo do ciclo anual, fenômeno que se denomina ritmo fenológico.

\section{Dimensão humana no Pantanal: turismo, natureza e benefícios socioeconômicos}

Em nome do chamado desenvolvimento, os ecossistemas naturais do Pantanal podem ser modificados e destruídos? É fato que o Pantanal tem sofrido grande número de ameaças ambientais, entre elas desmatamentos na própria área inundável, como também no planalto do entorno, onde nascem os rios da margem esquerda do Rio Paraguai, os quais descarregam suas águas na planície; introdução de espécies exóticas, como forrageiras para pasto do gado, substituindo a vegetação natural; poluição de águas por deficiência ou ausência de sistema sanitário, e tantas outras ameaças ambientais.

Não somente é o desmatamento com conversão radical da vegetação original que impacta a biodiversidade. A alteração parcial pelo corte seletivo de árvores para suprir de madeira as fazendas para cercas e outros usos também afeta a biodiversidade. Isso tem sido verificado nas pousadas do Pantanal. Um exemplo que tem sido bastante notado, e que ilustra esta ameaça, é o caso do corte de árvores maduras, como é o caso do manduvi, cujo oco serve de nicho ecológico para ninho da arara-azul e outros animais silvestres, e também suas sementes servem de alimento para o bugio. A proteção da oferta de nicho reprodutivo é essencial para a manutenção de espécies da biodiversidade.

Grandes centros urbanos, como Corumbá, Cuiabá, Cáceres e muitos outros, localizam-se às margens dos rios que inundam a planície, com infraestrutura sanitária deficiente, que despejam dejetos nos rios, afetando a qualidade da água.

Quem percorre o Pantanal pelas grandes rodovias, como a Transpantaneira, no Mato Grosso, e a Estrada Parque no Mato Grosso do Sul, depara-se, com frequência, com atropelamento de fauna silvestre.

A pesca comercial, esportiva e de subsistência é também fator socioeconômico importante para o Pantanal. No entanto, o estoque pesqueiro tem diminuído e a sobrepesca tem sido evidenciada para algumas espécies de peixes (Alho \& Reis, 2017: 27). 
A alteração de habitats e o desmatamento têm afetado os ambientes terrestres e aquáticos e a biodiversidade associada a eles. O fogo tem sido usado pelos fazendeiros na época da seca. A dinâmica de enchente tem sido ameaçada por obras de infraestrutura, como pequenas centrais hidrelétricas, estradas e outras.

O Pantanal tem experimentado a introdução de espécies exóticas tais como duas espécies de forrageiras africanas, as braquiárias, que cobrem agressivamente o solo e têm sido amplamente usadas pelos fazendeiros criadores de gado para converter a vegetação natural em pastagens cultivadas.

O porco comum, que se torna feral, localmente chamado de porco-monteiro, é comumente visto nas grandes áreas abertas do Pantanal. Ultimamente, há crescente preocupação com a expansão do javali, possivelmente fugido de criadouros.

O mexilhão dourado é um molusco asiático que alcançou as águas do Pantanal através do sistema Prata-Paraguai, e tem-se disseminado na região, interferindo na estrutura e função dos habitats aquáticos. Os peixes amazônicos tucunaré e tambaqui foram introduzidos nos rios pantaneiros, o que contribui para alterar a comunidade regional de peixes.

Durante o início da estação de cheia, quando a água do rio, na região da planície, começa a extravasar, saindo do leito para inundar a floresta ripária, alguns peixes deixam o leito do rio para explorar a área inundada da floresta. Esse é o caso do pacu, um dos peixes mais importantes do Pantanal sob o enfoque socioeconômico. O principal item alimentar do pacu é a semente da palmeira nativa das florestas ripárias. Portanto, o desmatamento dessas florestas afeta diretamente peixes e outras espécies da biodiversidade.

Geralmente, onde se localizam as instalações que recebem turistas que buscam a pesca esportiva, há gente local encarregada da captura de iscas vivas para serem fornecidas às pousadas, as quais revendem essas iscas aos turistas. Isso é parte de um mercado crescente, em função do incremento da pesca esportiva e, portanto, há uma crescente demanda por iscas vivas. Essas iscas são pequenos peixes como tuvira, cascudo, mussum e caranguejos dentre outros organismos, que vivem em ambientes de área de inundação rasa, de pouca correnteza, das "baías", corixos, vazantes e rios, dominados por vegetação aquática, as macrófitas aquáticas, localmente conhecidas como camalotes, baceiros e batumes. Aqui, pelo menos dois impactos negativos são observados:

i. a intensa captura, até mesmo à exaustão, dessas espécies que servem como iscas vivas; e 
ii. o efeito sobre a degradação do habitat e toda a comunidade ecológica da qual fazem parte integrante essas espécies.

Se, por um lado, os coletores se beneficiam dessa captura para sua subsistência, por outro, há de se buscar um meio sustentável de se utilizar esse recurso da biodiversidade regional relacionada ao turismo da pesca esportiva.

Quando há pesca sem controle, exaurindo os cardumes e reduzindo o tamanho dos peixes capturados, caracterizando a pesca predatória, há evidência da sobrepesca (Alho \& Reis, 2017: 27). Ainda, nas fazendas, em pousadas para turistas e em barcos para pesca esportiva não há coleta nem tratamento adequado do lixo e outros dejetos produzidos. No rio Paraguai, perto de Corumbá, é notável o aumento de resíduos sólidos no leito e nas margens do rio, a partir do período da abertura da pesca. Alguns barcos de pesca ou hotéis flutuantes, para a pesca esportiva, também exploram o turismo sexual.

Esse conflito da postura ambivalente entre desenvolvimento socioeconômico tradicional e natureza protegida pode ter uma opção de equilíbrio por meio do turismo sustentável.

O turista fica entusiasmado quando tem a oportunidade de ver e fotografar uma onça no Pantanal, que representa o poder e esplendor do predador-topo da cadeia trófica. Contudo, o turista quer ver esse ícone como um elemento importante do ecossistema local. Quando uma espécie como essa fica localmente extinta ou, por outro lado, sua presença é resultado de artifícios especiais, alheios à conservação da natureza, o ecossistema é afetado, perdendo assim a medida de sua significância.

Um dos problemas que se verificam no Pantanal é o hábito de os agentes das pousadas fazerem o que denominam "ceva", para atrair animais silvestres para suas propriedades, a fim de serem vistos e fotografados por turistas. Os órgãos ambientais locais dizem que oferecer alimento ou ceva para animais com o fim de abate pela caça é infração, mas isso não se aplica à ceva para observação e fotografia. De fato, em algumas fazendas que exploram o turismo no Pantanal é comum o emprego de ceva. Para atrair a arara-azul-grande, por exemplo, usa-se o fruto do acuri, alimento preferido pelas araras. Em alguns locais, oferece-se alimento até para a onça, como atrativo.

A biodiversidade do Pantanal não é só fonte de admiração e fascínio científico. Os vigorosos recursos biológicos que ocorrem no bioma têm contribuído para o bem-estar da gente local (Alho, 2012: 153) e para o incremento do turismo, particu- 
larmente para os que procuram o deleite de apreciar e fotografar a fauna silvestre (Tortato et alii, 2017: 110).

Na visão utilitária, a terra degradada pelo homem reduz sua capacidade de prover serviços ecossistêmicos; na visão ecológica, os impactos afetam função e estrutura intrínsecas dos ecossistemas naturais, das quais a biodiversidade é parte fundamental.

Algumas ameaças ambientais são de natureza técnico-científica, como aquelas que influenciam a estrutura e a função dos ecossistemas. Outras são de natureza política e administrativa e podem frequentemente ser evitadas, como o controle e a gestão das instalações e atividades turísticas,os padrões de pesca predatória e ilegal, o controle de desmatamento ilegal e outras ações que podem ser controladas.

É relevante para o turista na natureza explorar o significado, o mecanismo da biodiversidade em relação à complexa cadeia da vida silvestre. O turista na natureza se entretém com a experiência espetacular da paisagem, com a identidade ambiental, incluindo também a cultura da gente local. Desse modo, é implícito que o entretenimento seja feito num contexto de educação ambiental. Implica em responsabilidade ambiental.

O turismo no Brasil é regulado pela Lei federal 11.771, de 17 de setembro de 2008, que define as atribuições do governo Federal no planejamento, desenvolvimento e estímulo ao setor turístico. O Ministério do Turismo tem programação para implementar e incentivar o turismo. Por sua vez, os dois estados que compartilham território no Pantanal, o Mato Grosso conta com a Secretaria Adjunta de Turismo, e o Mato Grosso do Sul com a Fundação de Turismo de Mato Grosso do Sul.

As normas e diretrizes ditadas pelos órgãos turísticos ficam absolutamente distantes do que se observa no campo, sem implementação prática. Embora tenha havido seminários, palestras, programas e outras ações para promover o turismo no Pantanal, com raríssimas exceções, essas ações não gozam de implementação em face da realidade que se observa no campo.

É esperado que as comunidades locais que exploram o turismo no Pantanal tenham o compromisso óbvio de obedecerem às normas existentes. Idealmente, ao se estabelecerem as bases físicas e programáticas para se explorar o turismo na natureza, incluindo aqui o proprietário da terra e seus empregados como guias turísticos, e considerando que o principal produto desse mercado é a natureza protegida, não seria mais necessário se buscar pretenso apelo de conscientização ambiental ou 
aplicação da legislação ou regras para garantir a exploração por meio do turismo sustentável. Distante desse ideal, o presente meio de exploração do turismo no Pantanal carece de um plano de ação com a participação efetiva do Estado.

\section{Conclusão}

Fica evidente, diante da expansão do turismo na natureza no Pantanal, que seus benefícios socioeconômicos só podem ser eficazes se houver apoio à conservação da natureza. Fica relevante também que o turismo é uma das diversas opções para o desenvolvimento socioeconômico regional em apoio adicional à proteção da natureza.

Quando a biodiversidade é afetada e reduzida, com a alteração e eliminação de habitats naturais, ocorre o rompimento de um elo importante na teia da vida, produzindo efeitos desastrosos para a forma e função do ecossistema. Este é um efeito ecológico, independente do aspecto moral ou ético, ou mesmo da fragilidade de aplicação da legislação pelo Estado.

Verifica-se a fragilidade da aplicação da legislação em virtude da fraca estrutura institucional para o meio ambiente e para o turismo. A fiscalização é inadequada ou mesmo ausente. O conflito entre a expansão do turismo na natureza e a necessária proteção da natureza é evidente.

A variável da ameaça ambiental se traduz na integração:

i. com os componentes físicos e químicos (habitat natural, fluxo de nutrientes, solo, qualidade da água etc.);

ii. com o componente biótico (ocorrência de plantas e animais terrestres e aquáticos, diferentes tipos de cobertura vegetal natural etc.); e

iii. com elementos socioeconômicos (atração do turista pela fauna silvestre,pesca comercial e esportiva, extração de produtos naturais, pecuária etc.).

Serviços ecossistêmicos são definidos como benefícios para o homem, derivados da função e dos processos ecossistêmicos. A função ecossistêmica é a habilidade dos processos naturais de prover bens e serviços para a necessidade humana. São atributos que a função e o processo do ecossistema natural fornecem como valores para o homem como turismo na natureza, pesca, madeira, água, ar puro, medicamentos e outros. 
Sob o ponto de vista socioeconômico, turismo, pecuária, cultivo de soja, pesca comercial e esportiva, e outras atividades produtivas são importantes, pois necessárias para proverem recurso econômico e progresso social para a região. Contudo, o mercado não pode se sobrepor aos problemas ambientais, que também afetam fatores socioeconômicos, com perda da biodiversidade e de serviços ecossistêmicos. A via pragmática da conservação deve abranger, além do benefício socioeconômico, também a dimensão ética e a proteção ambiental, para o foco do desenvolvimento sustentável. O turismo na natureza promove uma alternativa para a elevação do padrão de vida dos fazendeiros e de seus empregados, produzindo benefícios para a gente local. No entanto, há imperativos ambientais e sociais associados ao turismo sustentável.

As ameaças à natureza estão em geral relacionadas ao controle ineficaz e à carência da aplicação da legislação existente, por conta da pobre infraestrutura institucional encarregada de aplicar a legislação e fiscalizar o extenso Pantanal.

O plano de ação para conservação deve integrar os atores envolvidos, na busca da implementação da legislação e instruções normativas, incluindo fiscalização e controle.

Dentre os grandes projetos executados no Pantanal e que tratam de algum modo da questão do turismo citam-se:

i. o Estudo para o Desenvolvimento Integrado da Bacia do Alto Paraguai (Edibap), executado entre 1977 e 1989;

ii. o Plano para a Conservação da Bacia do Alto Paraguai (PCBAP), de 1997;

iii. o Programa de Ações Estratégicas para o Gerenciamento Integrado do Pantanal e Bacia do Alto Paraguai (GEF-Pantanal (ANA/GEF/ Unep/OAS), executado pela Agência Nacional de Águas (ANA), com o apoio de instituições internacionais, de 2005.

Mais uma vez, são planos muito bons, mas que carecem da implementação prática das ações propostas.

No entanto, somente informações técnico-científicas não são suficientes para enfrentar o desafio do turismo sustentável. O conhecimento científico é fundamental para alavancar programas, mas torna-se necessário um plano de ação pragmático a ser executado. 
O plano de gestão para o turismo na natureza deve enfrentar algumas dificuldades inerentes, tais como:

i. carência político-institucional relacionada ao tema e conhecimento insuficiente por parte dos tomadores de decisão com respeito à multiplicidade de fatores envolvidos;

ii. carência na habilidade das comunidades humanas locais e dos outros atores envolvidos para estarem preparados e efetivamente participarem do plano de ações; e

iii. motivação política insuficiente e baixos níveis de participação da cidadania.

Torna-se necessário entender como a gente do Pantanal percebe o seu meio ambiente. Como isso é praticado no dia a dia, com base em valores econômicos e sociais. Idealmente, será útil confrontar esses valores com valores éticos, no plano de ação, no sentido de verificar como tais valores influenciam a tomada de decisão na busca do turismo sustentável.

Haverá sempre custos ambientais e benefícios socioeconômicos. O desafio é atingir um equilíbrio aceitável entre esses valores. Recursos da natureza que são abertos à exploração não regulada fatalmente tendem à degradação.

Finalmente, há pelo menos duas razões para otimismo:

i. a crescente expansão do turismo na natureza no Pantanal; e

ii. a crescente certeza de que o turismo sustentável pode também promover benefícios socioeconômicos como alternativa viável de desenvolvimento e valoração dos povos regionais.

A natureza protegida é mais do que importante, é vital para o turismo na natureza. As paisagens naturais e a fauna silvestre passam a ter valor econômico, porque são os objetos procurados, constituindo as mercadorias a serem vendidas ao turista.

O turismo na natureza - ou turismo ecológico, ou, ainda, ecoturismo - progride no mundo todo para alcançar um nível de maturidade. Quatro pilares sustentam o ecoturismo:

i. a minimização dos impactos ambientais negativos;

ii. o respeito às culturas regionais; 
iii. a maximização dos benefícios para a gente local; e

iv. a maximização da satisfação do turista.

Contudo, esses pilares encontram alguma dificuldade de implementação. Por exemplo, a estrita interpretação do turismo com foco na natureza protegida tem ou não consenso com relação à satisfação do turista, com ligação ainda à responsabilidade ambiental? Há participantes da gestão do ecoturismo que acreditam sim, que há o dever de se alcançar o turismo sustentável sob o enfoque ambiental, social e cultural. Contudo, outros levantam a dificuldade do alcance desses postulados. Ao observar a literatura publicada, conclui-se que o ecoturismo tem a natureza como foco de motivação do turista, na busca de sustentabilidade ambiental, social e cultural, mas ainda com alguma relação com o turismo de aventura.

O conceito original de ecoturismo define o turista viajando em busca de ambientes não degradados ou não contaminados, com o objetivo de estudar, admirar, e desfrutar do cenário com suas plantas e animais, como também das manifestações culturais do local. Contudo, em muitos locais, como no caso do Pantanal, o objetivo do ecoturismo é o de alcançar conservação da natureza com desenvolvimento socioeconômico. Neste caso, o turismo sustentável impõe uma obrigação ética com a natureza, que implica em consciência e educação ambiental, o que, ainda, exige a gestão governamental para manejo, monitoramento e implementação da legislação pertinente.

Instituições de governo como o Ministério do Turismo e os órgãos estaduais correspondentes devem fazer presença no sentido de cumprir ou fazer cumprir regras formais, tais como leis, instruções normativas e outras, e também informais, como recomendações de seminários, convenções, congressos, no sentido de determinar padrões de conduta para reduzir incertezas. Enfim, proporcionar estrutura eficiente de funcionamento do turismo para a sociedade. Assim, o Estado deve ter o papel de prover coordenação e fiscalização na gestão do turismo. Contudo, pelo que se constata na planície pantaneira, parece haver um vazio entre as prerrogativas do Estado e a real situação do turismo no Pantanal.

O plano de gestão do turismo na natureza para o Pantanal deve contar com a experiência das pousadas existentes, aliada às proposições dos agentes do Estado, no sentido não só de cumprir regras ou legislação, mas para se alcançar um plano de manejo simples e eficaz. Deve ser compatível com as diretrizes do Estado, em busca de sua sustentabilidade. Deve ressaltar a necessidade de conservação da natureza, sendo viável economicamente, com benefícios para os proprietários 
da terra e seus empregados locais. O plano de ação deve identificar os benefícios existentes, sem, contudo, ter visão imediatista, mas principalmente buscar sua manutenção futura e permanente. Deve buscar o equilíbrio do fluxo turístico, principalmente em locais sensíveis, como os "ninhais". Esse fluxo deve ainda ser considerado em função das diferentes estações do ano. O lucro obtido deve também dar apoio ao aperfeiçoamento dos planos de manejo em busca da duração em longo prazo e sustentável da atividade.

O significado socioeconômico do turismo no Pantanal aponta claramente para os benefícios do proprietário da terra e para a gente local. Nesse sentido, o plano de manejo deve também incentivar a cultura regional. Como já ressaltado, a atividade deve ser recreativa, mas também informativa e educativa. Adicionalmente, seria desejável poder contar com o reforço de ações que promovam conscientização e educação ambiental, como a elaboração de folhetos educativos com informações sobre os ecossistemas, a biodiversidade, o homem pantaneiro, com o objetivo de oferecer ao turista a oportunidade de se educar e melhor aprender sobre a ecologia e a cultura regional.

\section{Referências}

ALHO, Cleber J. R. Importance of biodiversity for the human health: an ecological perspective. Estudos Avançados (USP), v. 26, p.151-165, 2012.

- The Pantanal. In: FRASER, L. H.; KEDDY. P. A. (Orgs.). The world's largest wetlands - ecology and conservation. Cambridge (MA): Cambridge University Press, 2005.

ALHO, Cleber J. R.; PASSOS, Fernando. Primates of the South American Pantanal wetland: seasonal effects on their habitats and habits. In: NOWAK, K.; BARNETT, A.; MATSUDA, I. (Eds.). Primates in flooded habitats: ecology and conservation, p. 163-171. Cambridge (MA): Cambridge University Press, 2019.

ALHO, Cleber J. R.; REIS, Roberto E. Exposure of fishery resources to environmental and socioeconomic threats within the Pantanal wetland of South America. International Journal of Aquaculture and Fishery Science, v. 3, n. 2, p. 22-29, 2017.

ALHO, Cleber J. R.; SILVA, João S. V. Effects of severe floods and droughts on wildlife of the Pantanal wetland (Brazil). A Review. Animals, v. 2, p. 591-610, 2012.

ALHO, Cleber J. R.; LACHER Jr., Thomas E.; GONÇALVES, Humberto C. Environmental degradation in the Pantanal ecosystem. BioScience, v. 38, p. 164-171, 1988. 
ALHO, Cleber J. R.; CAMARGO, George; FISCHER, Erich. Terrestrial and aquatic mammals of the Pantanal. Brazilian Journal of Biology (Revista Brasileira de Biologia), v. 71, p. 297-310, 2011.

BRASIL. Ministério do Turismo. Turismo injetou US\$ 163 bilhões no Brasil em 2017. 2018. Disponível em: <http://www.turismo.gov.br/ultimas-noticias/11037-turismo-injetou-us\$-163-bilhoes-no-brasil-em-2017.html>. Acesso em: 23. Mar. 2019.

. Ministério do Turismo. Índice de competitividade do turismo nacional - Cuiabá. 2015. Disponível em: <http://www.turismo.gov.br/sites/default/turismo/o_ministerio/publicacoes/Indice_competitividade/2015/Cuiaba_RA_2015. pdf>. Acesso em: 23 Mar. 2019.

BRITSKI, Heraldo A.; SILIMON, Keve Z. S.; LOPES, Balzac S. Peixes do Pantanal: manual de identificação. 2. ed. Brasília: Embrapa Informação Tecnológica, 2007.

CAMPO GRANDE NEWS. Turismo no Pantanal cresce 4,5\% e movimenta R\$ 316 miIhões em 2014. 2015. Disponível em: <https://www.campograndenews.com.br/ cidades/interior/turismo-no-pantanal-cresce-4-5-e-movimenta-rs-316-milhoes-em-2014>. Acesso em: 23 Mar. 2019.

KRCMÁROVÁ, Jana. E. O. Wilson's concept of biophilia and the environmental movement in the U.S.A. Klaudyán: Internet Journal of Historical Geography and Environmental History, v. 6, n. 1-2, p. 4-17, 2009.

LOPES, Odiléia E.; SASSI, Onofre C. A importância do desenvolvimento da atividade turística pautada na educação ambiental e na ética. Revista Saber Acadêmico, n. 12, p. 5-9, Jun. 2011.

MAMEDE, Simone B.; ALHO, Cleber J. R. Response of wild mammals to seasonal shrinking-and-expansion of habitats due to flooding regime of the Pantanal, Brazil. Brazilian Journal of Biology (Revista Brasileira de Biologia), v. 66, p. 991-998, 2006.

NUNES, Alessandro P.; TOMAS, Walfrido M. Aves migratórias ocorrentes no Pantanal. "Documento 62". Corumbá: Embrapa Pantanal, 2004.

POTT, Vali J.; POTT, Arnildo; LIMA, L. C. P.; MOREIRA, S.N.; OLIVEIRA, Ademir K. M. Aquatic macrophyte diversity of the Pantanal wetland and upper basin. Brazilian Journal of Biology (Revista Brasileira de Biologia), v. 71 Suplemento, p. 255-263; 2011.

POTT, Arnildo; OLIVEIRA, Ademir K. M.; DAMASCENO JÚNIOR, Geraldo A.; SILVA, João S. V. Plant diversity of the Pantanal wetland. Brazilian Journal of Biology (Revista Brasileira de Biologia), v. 71 Suplemento, p. 265-273, 2011. 
SABINO, José; ANDRADE, Luciana P.; BESSA, Eduardo. Ecoturismo: valorizar a natureza para gerar negócios sustentáveis e renda. In: SABINO, J. Ecoturismo: nas trilhas da biodiversidade brasileira, p. 13-21. Campo Grande: Natureza em Foco, v. 1, 2012.

SCREMIN-DIAS, Edna; LORENZ-LEMKE, Aline P.; OLIVEIRA, Ademir K. M. The floristic heterogeneity of the Pantanal and the occurrence of species with different adaptive strategies to water stress. Brazilian Journal of Biology (Revista Brasileira de Biologia), v. 71, p. 275-282, 2011.

SHARMA, Anupama; KUKREJA, Sumita; SHARMA, A. Role of tourism in social and economic development of society. International Journal of Advanced Research in Management and Social Sciences, v. 1, n. 3, p. 10-31, Sep. 2012.

STRÜSSMANN, Christine; RIBEIRO, Ricardo Alexandre Kawashita; FERREIRA, Vanda Lúcia; BÉDA, Arlindo de Figueiredo. Herpetofauna do Pantanal brasileiro. In: NASCIMENTO, L.; OLIVEIRA, M. E. (Orgs.). Herpetologia no Brasil II. Belo Horizonte: Sociedade Brasileira de Herpetologia, 2007.

TORTATO, Fernando R.; IZZO, Thiago J.; HOOGESTEIJN, Rafael; PERES, Carlos A. The numbers of the beast: valuation of jaguar (Panthera onca) tourism and cattle depredation in the Brazilian Pantanal. Global Ecology and Conservation, v. 11, p. 106-114, 2017.

UNWTO - WORLD TOURISM ORGANIZATION. International tourist arrivals reach 1.4 billion two years ahead of forecasts. 2019. Disponível em: <http://www2.unwto.org/press-release/2019-01-21/international-tourist-arrivals-reach-14-billion-two-years-ahead-forecasts>. Acesso em: 23 Mar. 2019.

WILSON, Edward O. The creation - an appeal to save life on Earth. New York: W. W. Norton \& Company, Inc., 2006.

WWF-BRASIL. Aves migratórias no Pantanal - distribuição de aves limícolas neárticas e outras espécies aquáticas no Pantanal. SERRANO, I. L. (Coord.), Brasília: WWF-Brasil, 2008. 